\title{
DÜBLIN
}

Technological University Dublin

ARROW@TU Dublin

2004-01-01

\section{Implementation of new modified Smith predictor designs}

\author{
Pauline Sourdille \\ Technological University Dublin \\ Aidan O'Dwyer \\ Technological University Dublin, aidan.odwyer@tudublin.ie
}

Follow this and additional works at: https://arrow.tudublin.ie/engscheleart

Part of the Controls and Control Theory Commons

\section{Recommended Citation}

Sourdille, Pauline and O'Dwyer, Aidan : Implementation of new modified Smith predictor designs, Proceedings of the Irish Signals and Systems Conference, pp. 284-289, Queens University Belfast, July,2004. doi:10.21427/w3t8-p051

This Conference Paper is brought to you for free and open access by the School of Electrical and Electronic Engineering at ARROW@TU Dublin. It has been accepted for inclusion in Conference papers by an authorized administrator of ARROW@TU Dublin. For more information, please contact arrow.admin@tudublin.ie, aisling.coyne@tudublin.ie,gerard.connolly@tudublin.ie.

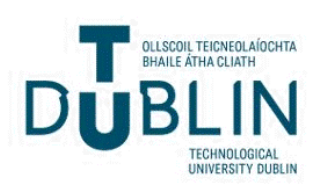




\title{
Implementation of New Modified Smith Predictor Designs
}

\author{
Pauline Sourdille ${ }^{\phi}$ and Aidan O'Dwyer* \\ ${ }^{\phi}$ School of Control Systems and Electrical \\ Engineering, \\ Dublin Institute of Technology, Kevin Street \\ Dublin 8, IRELAND \\ E-mail: ${ }^{\phi}$ pauline.sourdille@dit.ie \\ * School of Control Systems and Electrical \\ Engineering, \\ Dublin Institute of Technology, Kevin Street \\ Dublin 8, IRELAND \\ E-mail: ${ }^{\dagger}$ aidan.odwyer@dit.ie
}

\begin{abstract}
This paper outlines two modified Smith predictors developed previously by the authors and then presents the implementation results of these structures for the control of a pilot scale heating and ventilation system, the PT326 process trainer from Feedback Instruments Ltd. These results are compared to the results obtained with a Smith predictor structure.
\end{abstract}

Keywords - Dead-time compensator, process control.

\section{INTRODUCTION}

As it is well known, good control of processes with long time delay may be difficult using the PID algorithm. In 1957, O. J. Smith [1] developed the Smith predictor structure to compensate systems with time delay. Over the years, many modifications to the Smith predictor structure have been proposed to improve the servo response, the regulator response or both. Other modifications have adapted the Smith predictor structure for the control of stable, integrative or unstable processes. Implementation is an important issue for dead time compensators as it validates the design. The paper reviews the two modified Smith predictor structures developed previously by the authors [2-4], presents the simulation results and finally compares the different implementation results for the Smith predictor and the two modified Smith predictors, for the control of the PT326 process trainer. The original contributions compared to [2-4] are the validation of the tuning rules developed for the modified Smith predictor structures and the proof that the modified Smith predictor structures achieve better servo and regulator responses than the Smith predictor on a real process.

\section{MODIFIED SMITH PREDICTOR STRUCTURES}

Over fifty articles were studied to identify the different existing modifications of the Smith predictor. Sourdille and O'Dwyer [2] present an extensive literature review of these modifications. By combining several of the existing modified structures, which have common features, a generalised form of the Smith predictor is obtained. Figure 1 shows this generalised form.

The requirements specified for the general structure were to obtain perfect servo and regulator responses (i.e. $\frac{y_{p}}{r}=1$ and $\frac{y_{p}}{L}=0$ ), and that the controller transfer functions are only expressed in terms of the model parameters. It turns out that three primary controllers are needed: one to optimise the servo response, one to optimise the regulator response and one to reduce the mismatch between the process and the model. $\mathrm{G}_{\mathrm{c} 1}, \mathrm{G}_{\mathrm{c} 5}$ and $\mathrm{G}_{\mathrm{c} 6}$ are equal to 1 , and $\mathrm{G}_{\mathrm{c} 2}$, $\mathrm{G}_{\mathrm{c} 4}$ and $\mathrm{G}_{\mathrm{c} 3}$ are equal to 0 when they are not used.

After calculating each possible combination of controller triplets, fifteen cases are realisable. From these realisable cases, only two cases are considered (labelled modified Smith predictors) as their controller transfer functions are of the simplest form to limit any necessary approximations. 


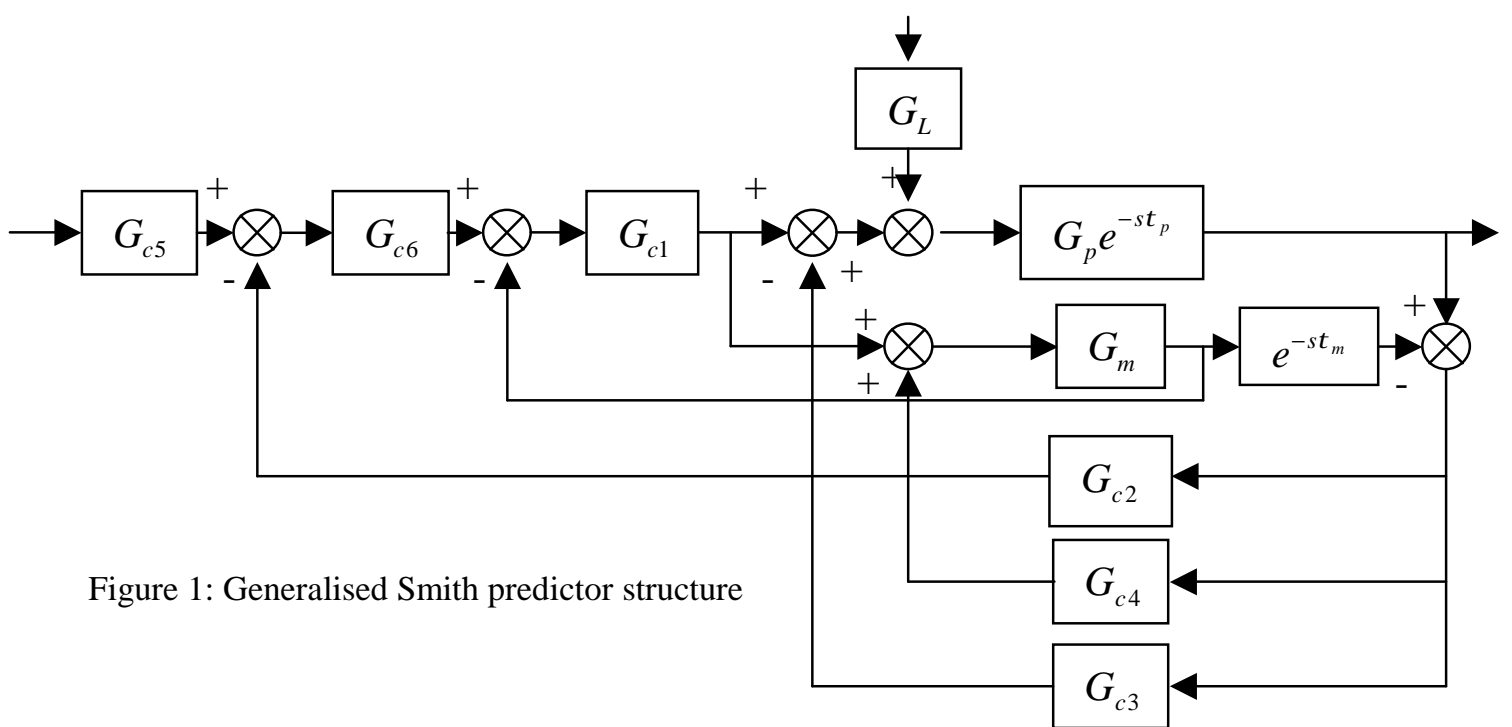

\section{a) First modified Smith predictor}

The first modified Smith predictor structure employs $\mathrm{G}_{\mathrm{c} 3}$, which optimises the servo response, $\mathrm{G}_{\mathrm{cl}}$, which optimises the regulator response and $\mathrm{G}_{\mathrm{c} 2}$, which reduces the mismatch term between the process and the process model. This structure is fully explained by Sourdille and O'Dwyer [2]. From this article, it is found that the controllers are given by equations (1), (2) and (3) and that the associated tuning rules, depending on the index $\tau_{m} / T_{m}$, are given by Table 1 with values of $\alpha$ and $p$ given by Table 2. (Note $\left.G_{m} e^{-s \tau_{m}}=\frac{K_{m}}{T_{m} s+1} e^{-s \tau_{m}}\right)$

$$
\begin{gathered}
G_{c 2}=0 \\
G_{c 1}=\frac{T_{m} s+1}{K_{m} T_{1} s} \\
\text { and } G_{c 3}=\frac{\alpha T_{m} s+1}{\alpha K_{m} T_{2} s} \frac{1+B(s)}{1+B(s) e^{-s \tau_{m}}} \\
\text { where } B(s)=\frac{T_{m} s+1}{T_{m} s+p} .
\end{gathered}
$$

Table 1: Tuning rules for the first modified Smith predictor

\begin{tabular}{ccc} 
& $\mathrm{G}_{\mathrm{c} 1}$ & $\mathrm{G}_{\mathrm{c} 3}$ \\
\hline $0<\frac{\tau_{m}}{T_{m}} \leq 0.5$ & $T_{1}=\frac{0.01 T_{m}}{K_{m}}$ & $T_{2}=\frac{T_{m}}{K_{m}}$ \\
$0.5<\frac{\tau_{m}}{T_{m}} \leq 1$ & $T_{1}=\frac{0.01 T_{m}}{K_{m}}$ & $T_{2}=T_{m}$ \\
$1<\frac{\tau_{m}}{T_{m}} \leq 2$ & $T_{1}=\frac{0.01 T_{m}}{K_{m}}$ & $T_{2}=\frac{5 T_{m}}{K_{m}}$ \\
\hline
\end{tabular}

Table 2: Range of values for $\alpha$ and $p$

\begin{tabular}{ccc} 
& $\alpha$ & $p$ \\
\hline $0<\frac{\tau_{m}}{T_{m}} \leq 0.5$ & $1 \leq \alpha \leq 2$ & $p=10$ \\
$0.5<\frac{\tau_{m}}{T_{m}} \leq 1$ & $\alpha=1.4$ & $p=4$ \\
$1<\frac{\tau_{m}}{T_{m}} \leq 2$ & $0.5 \leq \alpha \leq 1.5$ & $2 \leq p \leq 5$
\end{tabular}

From Table 2, it can be noticed that for the range $0.5<\frac{\tau_{m}}{T_{m}} \leq 1, \alpha$ and $\mathrm{p}$ have an unique value. This is because only one process of the seven benchmark processes corresponded to this range.

\section{b) Second modified Smith predictor}

The second modified Smith predictor structure employs $G_{c 3}$, which optimises the servo response, $\mathrm{G}_{\mathrm{c} 4}$, which optimises the regulator response and $\mathrm{G}_{\mathrm{c} 2}$, which reduces the mismatch term between the process and the process model. This modified Smith predictor is presented in detail by Sourdille and O'Dwyer [3]. This article explains the step by step procedure used to obtain the controller transfer functions given by equations (4), (5) and (6); the associated tuning rules depending on the index $\tau_{m} / T_{m}$, are given by Table 3, with values of $\alpha$ and $p$ given by Table 4 .

$$
\begin{gathered}
G_{c 2}=0 \\
G_{c 3}=\frac{T_{m} s+1}{\alpha K_{m} T_{2} s} \frac{1+B(s)}{1+B(s) e^{-s \tau_{m}}} \\
\text { and } G_{c 4}=-\frac{T_{m} s+1+K_{m}}{K_{m}\left(T_{1} s+K_{1}\right)} \frac{1+B(s)}{1+B(s) e^{-s \tau_{m}}}
\end{gathered}
$$


where $B(s)=\frac{T_{m} s+1}{T_{m} s+p}$.

In addition, a proportional controller, $\mathrm{K}_{\mathrm{c}}$, is introduced at the command signal to eliminate an offset observed in the servo and regulator responses.

Table 3: Tuning rules for the second modified Smith predictor

\begin{tabular}{lccc} 
& $\mathrm{K}_{\mathrm{c}}$ & $\mathrm{G}_{\mathrm{c} 3}$ & $\mathrm{G}_{\mathrm{c} 4}$ \\
\hline $0<\frac{\tau_{m}}{T_{m}} \leq 0.5$ & $\frac{K_{m}+1}{K_{m}}$ & $T_{2}=\frac{T_{m}}{K_{m}}$ & $T_{1}=50 T_{m}$ \\
$K_{1}=100$ \\
$0.5<\frac{\tau_{m}}{T_{m}} \leq 1$ & $\frac{K_{m}+1}{K_{m}}$ & $T_{2}=T_{m}$ & $T_{1}=50 T_{m}$ \\
$1<\frac{\tau_{m}}{T_{m}} \leq 2$ & $\frac{K_{m}+1}{K_{m}}$ & $T_{2}=\frac{5 T_{m}}{K_{m}}$ & $K_{1}=100$ \\
$K_{1}=100 T_{m}$ \\
\hline
\end{tabular}

Table 4: Range of values for $\alpha$ and $p$

\begin{tabular}{ccc} 
& $\alpha$ & $P$ \\
\hline $0<\frac{\tau_{m}}{T_{m}} \leq 0.5$ & $0.5 \leq \alpha \leq 2$ & $4 \leq p \leq 10$ \\
$0.5<\frac{\tau_{m}}{T_{m}} \leq 1$ & $\alpha=1.1$ & $p=3$ \\
$1<\frac{\tau_{m}}{T_{m}} \leq 2$ & $1 \leq \alpha \leq 2$ & $2 \leq p \leq 10$ \\
\hline
\end{tabular}

\section{SIMULATION RESULTS}

A summary of simulation results covered by seven benchmark processes and their models is presented. The process model parameters are obtained using an open loop frequency domain identification technique (O'Dwyer [5]). In the current research work, the simulations are run over a period of 100 seconds, with a step of unity applied at the input command signal to obtain the servo responses and at the disturbance input to obtain the regulator responses. The primary controller for the Smith predictor is designed to achieve perfect responses (i.e. $\frac{y_{p}}{r}=1$ and $\left.\frac{y_{p}}{L}=0\right)$. This gives a primary controller of the following form (equation (7)) and its implementable approximation is given by equation (8).

$$
\begin{aligned}
G_{c} & =-\frac{T_{m} s+1}{K_{m}\left(1-e^{-s \tau_{m}}\right)} \\
\text { and } G_{c} & =\frac{T_{m} s+1}{K_{m}(s+1)\left(1-e^{-s \tau_{m}}\right)}
\end{aligned}
$$

\section{a) First modified Smith predictor}

Table 5 shows the number of simulations in which improvement in response was detected, when the modified Smith predictor was used instead of the Smith predictor, with the responses evaluated using four indices (Integral Absolute Error-IAE, Integral Squared Error-ISE, Integral Time multiplied by Squared Error-ITSE and Integral of Squared Time multiplied by Squared Error-ISTSE). The indices are calculated from SIMULINK/MATLAB structures using the command and output signals. Three simulations are conducted on each of seven benchmark processes to obtain the results for varying values of the mismatch term $\left(G_{p} e^{-\tau_{p} s}-G_{m} e^{-s \tau_{m}}\right)$, i.e. the mismatch term may be small, negative or positive. This gives 21 simulation results altogether.

Table 5: Improvement in responses noted when the first modified Smith predictor is used

\begin{tabular}{lllll} 
& IAE & ISE & ITSE & ISTSE \\
\hline Servo responses & 20 & 21 & 20 & 17 \\
$\begin{array}{l}\text { Regulator } \\
\text { responses }\end{array}$ & 21 & 21 & 21 & 21 \\
$\begin{array}{l}\text { Corresponding } \\
\text { Percentage }\end{array}$ & $98 \%$ & $100 \%$ & $98 \%$ & $91 \%$ \\
\hline
\end{tabular}

For example, if the nominal process transfer function

is $G_{p} e^{-s \tau_{p}}=\frac{2}{s^{2}+s+1} e^{-s}$
$G_{p} e^{-s \tau_{p}} \in\left[\frac{1.6}{0.85 s^{2}+0.85 s+1} e^{-0.85 s}, \frac{2.8}{1.3 s^{2}+1.3 s+1} e^{-1.3 s}\right]$

(10-11) and the model transfer function is $G_{m} e^{-s \tau_{m}}=\frac{2.32}{1.17 s+1} e^{-1.66 s}$ (12), the Integral Square Error values for the Smith predictor and the first modified Smith predictor are given below.

Table 6: ISE values for Smith predictor and first modified Smith predictor

Smith predictor First modified

Mismatch Servo Regu. Servo Regu.

\begin{tabular}{lllll} 
term & & & & \\
\hline Small & 2.419 & 9.218 & 1.493 & 7.453 \\
Negative & 2.675 & 6.818 & 1.483 & 5.604 \\
Positive & 2.566 & 17.357 & 2.509 & 14.084 \\
\hline
\end{tabular}

\section{b) Second modified Smith predictor}

Table 7 shows the number of simulations, in which improvement in response was detected, when the modified Smith predictor was used instead of the Smith predictor, with the responses evaluated using the four indices. 
Table 7: Improvement in responses noted when the second modified Smith predictor is used

\begin{tabular}{|c|c|c|c|c|}
\hline & IAE & ISE & ITSE & ISTSE \\
\hline $\begin{array}{l}\text { Servo } \\
\text { responses }\end{array}$ & 18 & 14 & 17 & 15 \\
\hline $\begin{array}{l}\text { Regulator } \\
\text { responses }\end{array}$ & 21 & 21 & 19 & 18 \\
\hline $\begin{array}{l}\text { Corresponding } \\
\text { percentage }\end{array}$ & $93 \%$ & $83 \%$ & $85 \%$ & $79 \%$ \\
\hline
\end{tabular}

Using equations (9-12), the following Integral Square Error values may be obtained for the Smith predictor and second modified Smith predictor structures.

Table 8: ISE values for Smith predictor and second modified Smith predictor

Smith predictor

First modified

$\begin{array}{lll}\text { Mismatch Servo Regu. } & \text { Smith predictor } \\ \text { Servo Regu. }\end{array}$

\begin{tabular}{lllll} 
term & & & & \\
\hline Small & 2.419 & 9.218 & 1.748 & 6.685 \\
Negative & 2.675 & 6.817 & 1.721 & 4.687 \\
Positive & 2.566 & 17.357 & 3.077 & 17.162
\end{tabular}

From Tables 5 and 7, it may be concluded that better servo and regulator responses are achieved in the vast majority of cases when the modified Smith predictors are used instead of the corresponding Smith predictor, especially for regulator responses. This is significant, as it is recognised that the Smith predictor structure facilitates relatively poor regulator responses.

c) Comparison between the two modified Smith predictor structures

A comparison between the two modified Smith predictor structures is effected to evaluate which modified Smith predictor structure achieves better responses. This comparison is presented in detail by Sourdille and O'Dwyer [4]. Table 9 shows the number of simulations in which improvement in response was detected, when the first modified Smith predictor was used instead of the second modified Smith predictor, with the responses evaluated using the relevant indices.

Table 9: Improvement in responses noted when the first modified Smith predictor is used instead of the second modified Smith predictor

\begin{tabular}{lllll} 
& IAE & ISE & ITSE & ISTSE \\
\hline Servo & 19 & 20 & 18 & 16 \\
Regulator & 2 & 1 & 3 & 5 \\
\hline
\end{tabular}

Using Tables 6, 8 and 9, it can be broadly concluded that the first modified Smith predictor structure achieves better servo responses than the second modified Smith predictor structure while the second modified Smith predictor structure achieves better regulator responses.

The following figure shows a representative simulation result where $1<\frac{\tau_{m}}{T_{m}} \leq 2$ using equation (10) for the process transfer function and equation (12) for the model transfer function. The simulations are carried out in MATLAB/SIMULINK [6].

Figure 2: Servo and regulator responses
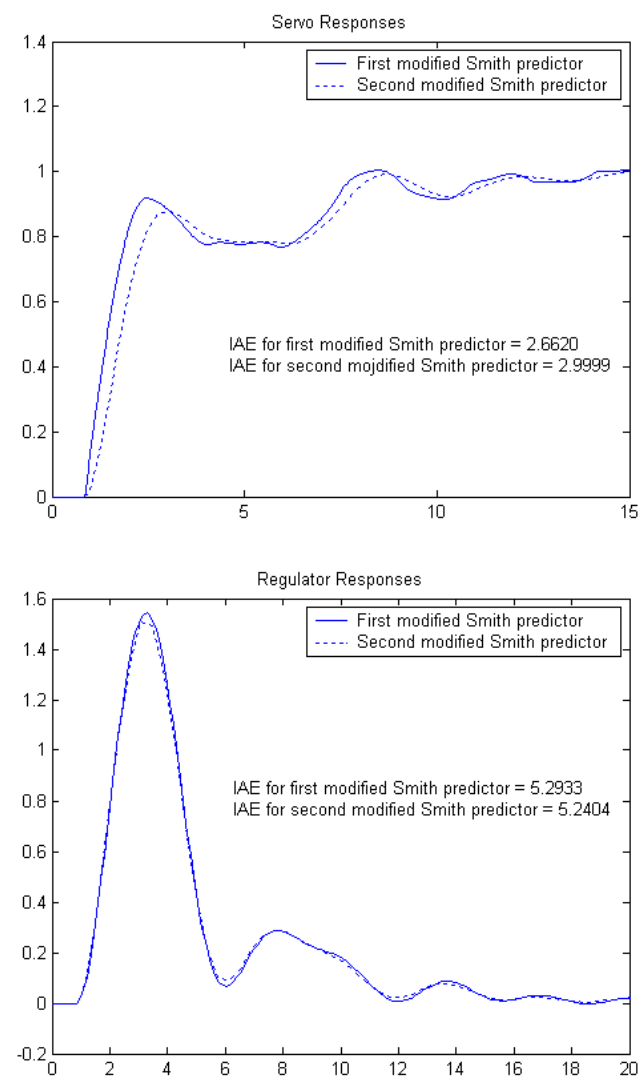

\section{IMPLEMENTATION RESULTS}

The Process Trainer PT326 (Serial number $326 / 74 / 5$ ), from Feedback Instruments Ltd, is used to validate the simulation results. In this equipment, the air drawn from the atmosphere by a centrifugal blower is driven past a heater grid and through a length of tubing before being returned to the atmosphere again. The air flowing is to be heated to a desired temperature level. A bead thermistor (detecting element) fitted to the end of a probe, is inserted into the air stream along the tube. Three different distances of the thermistor from the heater can be chosen: the thermistor can be close to the blower (small dead time), it can be in the middle of 
the tube and it can be at the end of the tube (long dead time). The process trainer with its data acquisition scheme may be represented by Figure 3 .

Figure 3: Feedback process Trainer PT 326 representation.

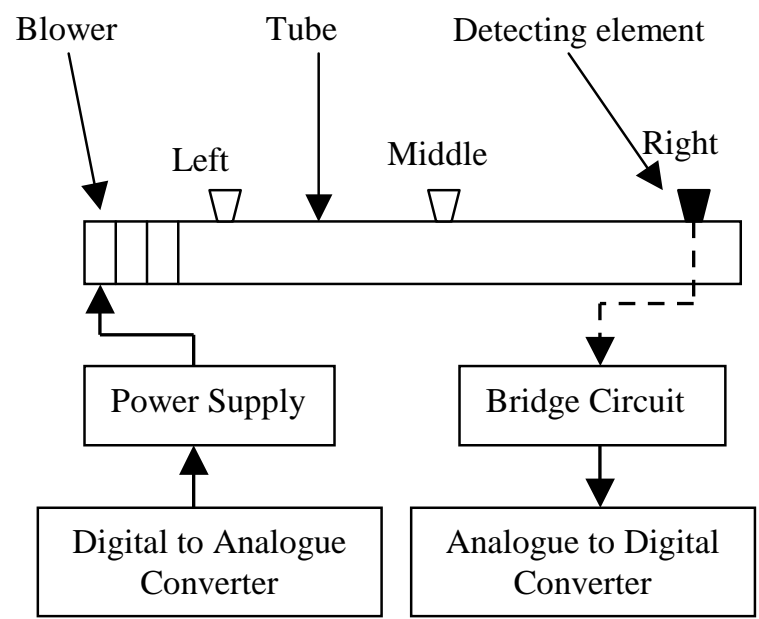

By analysing the relationship between step change in heater voltage and the process trainer temperature, it has been concluded that the process is non-linear for some operating conditions. For the implementation of the Smith predictor structures, it was decided to use the system only in its linear region.

As the Smith predictor is a model-based structure, the model of the process has to be determined. To do so, the process step response with the sensor in the middle position was recorded and the 2-point method was used (equations (13) and (14)) to determine the time constant and time delay of a first order lag plus delay (FOLPD) process model. The gain is determined using equation (15).

$$
\begin{gathered}
t_{28 \%}=\tau_{m}+\frac{T_{m}}{3} \\
t_{63 \%}=\tau_{m}+T_{m} \\
K_{m}=\frac{\text { change_in_controlled_variable }}{\text { change_in_manipulated_variable }}
\end{gathered}
$$

By re-arranging the above equations, the time constant and dead time of the process can be determined. As the process is very sensitive to changes in the room temperature, an averaging of over 20 different process step responses, at different times of the day, has been done to obtain the model transfer function given by equation (16).

$$
G_{m} e^{-s \tau_{m}}=\frac{0.76}{0.6 s+1} e^{-0.3 s}
$$

The comparison between the step response of the model and the process shows the validity of the model. For this comparison, the step input is applied at 50 seconds.
Figure 4: Comparison between the step responses of the model and the process

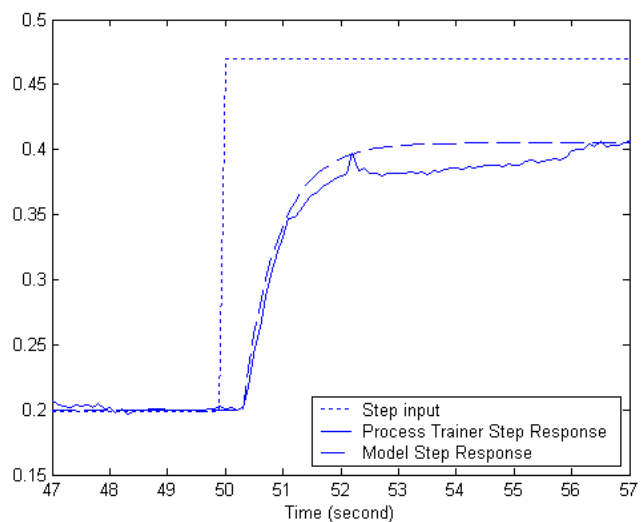

From the model transfer function, the index $\tau_{m} / T_{m}$ may be determined ( 0.5 for this process) and consequently the set of tuning rules to use for each structure is deduced. Since the value of $\tau_{m} / T_{m}$ is on the boundary of two ranges for the tuning rules, it was decided to tune the compensators using tuning rules for $0<\frac{\tau_{m}}{T_{m}} \leq 0.5$ and $0.5<\frac{\tau_{m}}{T_{m}} \leq 1$. In this paper, only the results for the tuning rules for $0<\frac{\tau_{m}}{T_{m}} \leq 0.5$ are presented for space reasons.

For the Smith predictor structure, equation (8) is used to specify the primary controller. Equations (2) and (3) are used to implement the first modified Smith predictor with $\alpha=1.2$ and $p=10$. Equations (5) and (6) are used to implement the second modified Smith predictor with $\alpha=0.75$ and $p=6$.

Using SIMULINK/MATLAB [6] in association with HUMUSOFT [7], it is possible to calculate, on-line, the values of the quality indices, such as the Integral Absolute Error index. Of course, the value of index recorded is dependent on external factors, such as ambient temperature; every effort was made to keep the ambient temperature constant during the course of the experiments. It was decided to reduce the effect of external variations by averaging the IAE value obtained from ten different experimental values.

Table 10 presents the values of the Integral Absolute Error recorded over a period of 50 seconds, associated with the three dead time compensators, for each position of the thermistor sensor with the model transfer function given by equation (16). The values in bold are the lowest values of the Integral Absolute Error for the servo and regulator responses. 
Table 10: IAE values for the three dead time compensators, as function of sensor position

\begin{tabular}{|c|c|c|c|c|c|c|}
\hline $\begin{array}{c}\text { Position } \\
\text { of sensor }\end{array}$ & \multicolumn{2}{|c|}{$\begin{array}{c}\text { Smith } \\
\text { predictor }\end{array}$} & \multicolumn{2}{c|}{$\begin{array}{c}\text { First } \\
\text { modified } \\
\text { Smith } \\
\text { predictor }\end{array}$} & \multicolumn{2}{|c|}{$\begin{array}{c}\text { Second } \\
\text { modified } \\
\text { Smith } \\
\text { predictor }\end{array}$} \\
\hline Responses & Ser. & Reg. & Ser. & Reg. & Ser. & Reg. \\
\hline Right & 0.76 & 0.50 & 0.40 & 0.32 & $\mathbf{0 . 3 5}$ & $\mathbf{0 . 2 7}$ \\
\hline Middle & 0.56 & 0.41 & 0.48 & 0.37 & $\mathbf{0 . 3 6}$ & $\mathbf{0 . 2 9}$ \\
\hline Left & 0.77 & 0.58 & 0.80 & 0.63 & $\mathbf{0 . 7 4}$ & $\mathbf{0 . 5 5}$ \\
\hline
\end{tabular}

As can be seen, the second modified Smith predictor achieves the best results for servo and regulator responses. Figures 5 and 6 show the servo and regulator responses for each structure with the thermistor sensor in the right position, representing the largest delay for the process for step input of 0.24 , which corresponds to a temperature change from $30^{\circ}$ to $35^{\circ}$.

Figure 5: Servo responses for the dead time compensators

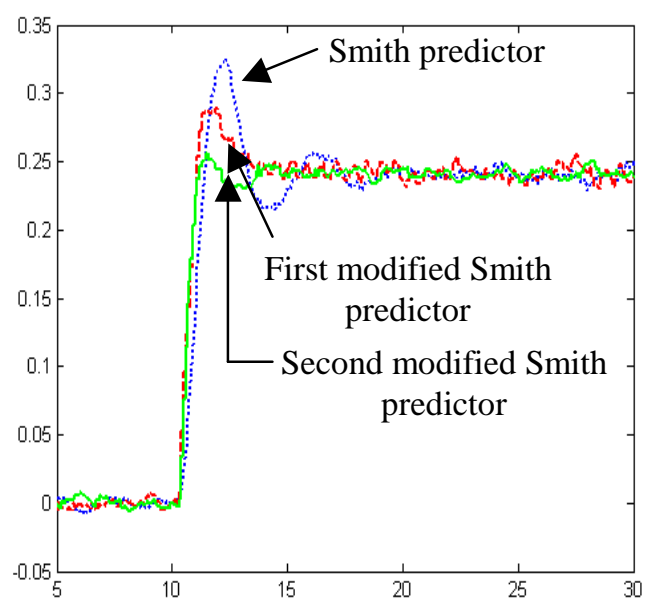

Figure 6: Regulator responses for the dead time compensators.

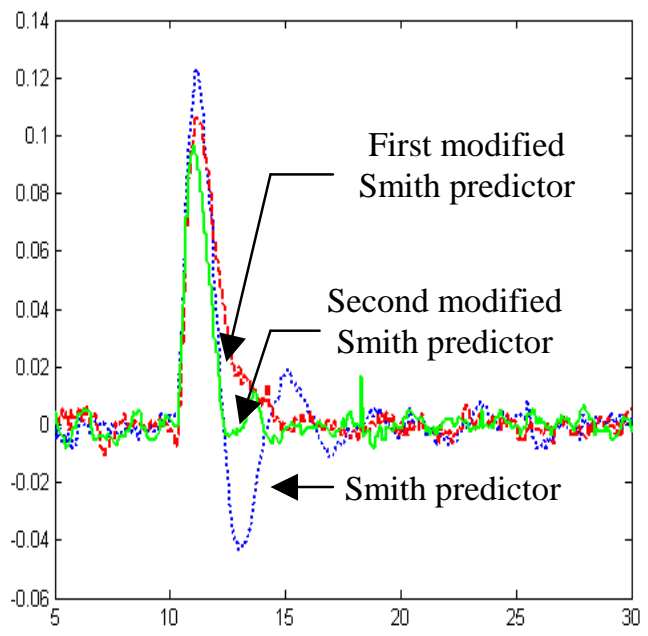

\section{CONCLUSION}

It has been shown that the first modified Smith predictor achieves the best servo responses and that the second modified Smith predictor achieves the best regulator responses, in a simulation context. From the implementation results, it can be concluded that the first and second modified Smith predictor achieves better servo and regulator responses than the Smith predictor for the three different positions of the thermistor sensor. It can also be concluded that the second modified Smith predictor achieves the best overall results for servo and regulator responses. It can be noticed that the modified Smith predictor structures are simple to tune, with just two tuning parameters. It also is sensible to conclude that the modified Smith predictors show some robustness to the process/model mismatch term.

\section{REFERENCES}

[1] Smith, O.J.M. "Closer control of loops with dead time”. Chemical Engineering Progress, 53, 217 219, 1957.

[2] Sourdille, P. and O'Dwyer, A. "An outline and further development of Smith predictor based methods for compensation of processes with time delay". Irish Signals and Systems Conference, Limerick, Ireland ,pp. 338-343, 2003.

[3] Sourdille, P. and O'Dwyer, A. "A new modified Smith predictor Design". International Symposium on Information and Communication Technologies Conference,Trinity College, Dublin, Ireland ,pp.404-409, 2003.

[4] Sourdille, P. and O'Dwyer, A. "New modified smith predictor designs". International Federation of Automatic Control workshop on Time-delay systems, INRIA, Rocquencourt, France, 2003

[5] O’Dwyer, A. "A Frequency domain technique for the estimation of the parameters of a delayed process". Transaction of Institute of Measurement and Control, 24, 4, 277-288, 2002.

[6] SIMULINK/MATLAB. www.mathworks.com [7] HUMUSOFT. www.humusoft.com 